\title{
THE VIRTUE EPISTEMOLOGISTS. INTERVIEW WITH ERNEST SOSA
}

LOS EPISTEMOLÓGOS DE LAS VIRTUDES. ENTREVISTA A ERNESTO SOSA

Interview by Richard Marshall ${ }^{1}$

3:AM: What made you become a philosopher?

Ernest Sosa: In my college years I was often intrigued by philosophical questions that my fellow students dismissed. At that point I had not come across "philosophy," so named. Only right before my senior year did I find Bertrand Russell, which led to a year full of philosophy (almost exclusively) at the University of Miami, with Ramon Lemos as main professor, then two years of graduate work at the ascendant University of Pittsburgh, with Nicholas Rescher as main professor, followed by a year of full time teaching at the University of Western Ontario and a two-year postdoc at Brown, with Roderick Chisholm as mentor. (Short graduate careers were not unusual in those days of enormous growth in higher education.)

I became and remained a philosopher because, through their writings, teaching, and discussion, brilliant people nourished and shared the philosophical curiosity that came so naturally to me.

3:AM: You've taken on epistemic skeptics who wonder whether we can know that this isn't all a dream and so forth. You did so by putting forward your own theory of epistemology — a virtue epistemology that you see as being in line with theories of knowledge put forward by Aristotle, Aquinas, Reid and Descartes. Can you sketch for us what virtue epistemology is and in particular the distinction between animal and reflective knowledge? And is it a modern version of Reid's common sense approach-or Moore's?

ES: I like the common sense approach of Reid and Moore, methodologically and metaphysically. But the history of astronomy soon made it irresistible that

\footnotetext{
${ }^{1}$ Entrevista publicada en la revista 3:AM el 16 de septiembre de 2016. http://www.3ammagazine.com/3am/the-virtue-epistemologist/

Los editores quieren agradecer a Richard Marshall su consentimiento para reproducirla aquí.
} 
common sense can be shown by science to be flatly wrong. Any defense of common sense must allow that it is revisable. Ultimately, my more significant agreement is with a virtue tradition that features Aristotle and Descartes.

Knowledge in my view is a form of action. It involves endeavors to get it right, and more broadly it concerns aimings, which can be functional rather than intentional. Through our perceptual systems, we represent our surroundings, aiming to do so accurately, where the aiming is functional or teleological, rather than intentional. And the same goes for our functional beliefs. Through our judgments, however, we do intentionally, even consciously, attempt to get it right. What follows will focus on these epistemic intentional attempts, but the account to be sketched generalizes to the broader category of aimings, which need not be intentional.

Attempts bring with them a distinctive normativity of attempts as attempts. For example, success is better than failure; an attempt is a better attempt, it is better as an attempt, if competent than if incompetent; and it is better to succeed through competence - aptly — than through sheer luck. (Here I stipulate, for the sake of a handy label, that an attempt is "apt" if, and only if, its success manifests the agent's pertinent competence.) Here we have a telic normativity in contrast with the deontic normativity of norms, obligations, permissions, and so on.

Attempts are found in domains of human performance, such as sports, games, artistic domains, professional domains like medicine and the law, and so on. These feature distinctive aims, and corresponding competences. Archery, with its distinctive arrows and targets, divides into subdomains. Thus, competitive archery differs importantly from archery hunting. In competitive archery, risk assessment has minimal bearing on quality of performance, since the archer has so little choice over shot selection. By contrast, in a hunt, shots vary in quality according to how well selected they may be.

Domains come thus in three sorts, distinguished by how their distinctive attempts are regulated by standards of appropriate risk.

A domain can be entirely unregulated with respect to appropriate risk, so that participant agents need pay no heed to any such standards. Take doodling, or "aimless" ambling in a safe riverside meadow, or drifting in a canoe on a placid lake. Here standards of risk are minimal or nonexistent. Normal adults can doodle, amble, and drift with no need to assess risk, since there is normally no risk at all. Jazz improvisation seems less subject to standards of risk than surgery, and less than much formal athletic performance, as in a tennis match.

A domain can be risk-unregulated in a different way, when participants are not allowed attempt selection, or are tightly restricted, as in competition archery. When 
it is an archer's turn he must put himself in position and shoot, with minimal, highly restricted attempt selection. At that point he must take aim and shoot. $\mathrm{He}$ has minimal or zero discretion with regard to the normal factors of Situation (distance, light), or Shape (no option to wait til less tired, more alert, etc.), or Skill (can't postpone so as to hone skill). And these are the SSS factors that determine degree of complete competence.

The third category is of domains risk-regulated to a significant extent, some highly so. Professional domains are examples here, reaching a peak in invasive surgery. Other examples are sports such as tennis and basketball.

The archery hunt is a borderline case. How is Diana's shot selection regulated? This depends on whether the hunt is nearing its end, how many arrows are left in her quiver, and the like. A shot that she takes with the one arrow left to her may allow less risk than one taken when the quiver is full, especially if the success of the afternoon's hunt depends on her success with that one remaining arrow. Hunt-internal factors determine appropriate risk in a way that would tend to elicit broad agreement among knowledgeable observers. Risk may be obviously too high when she is too far from her target, with just one arrow left, and when it is likely enough that better targets will soon be available within better range in the woods teeming with game.

A shot by Diana might be deft while poorly selected, an inferior shot in that respect - if the prey is far, visibility poor, and the wind blowing hard, so that likelihood of success is extremely low. Still her dexterity as an archer might deliver the success of her shot, a highly skilled shot (in respect of manual skill) despite being so poorly selected, so ill-judged (in respect of risk assessment). Diana's shot may thus attain first-order aptness through dexterity, without attaining "reflective" aptness full well. The latter requires aptness not only in hitting the target through manual competence, but also in attaining the aptness of one's shot, not only through dexterity but also through risk assessment.

Archery-external pragmatic values are here irrelevant, even when they do bear on the overall assessment of a hunter's archery shot. Thus, the success of an archery shot may bring food to the hunter's starving family, or may constitute a horrible murder. But these outcomes are irrelevant to the assessment of that shot as a hunter-archery shot, as an attempt to hit prey without running excessive risk of failure.

Accordingly, I leave open what value external to hunting-archery may reside in the fully apt success of such an archery shot. I put aside even whatever valuewhether final or inherent or intrinsic - axiology might attribute to such archery 
shots and to fully apt ones in particular. That is independent of the normativity of hunting archery attempts as such attempts. The latter normativity is determined by the aims constitutive of hunting archery attempts as such, both of such attempts that aim merely at success, and also those that aim at apt success. If a shot aimed at aptness succeeds aptly, it is then fully apt, since it is not only apt but also aptly apt.

But the full aptness of such an attempt is entirely compatible with its being a horrible murder, if the "hunter" is an assassin and the prey his victim. That hunter's shot may still be outstandingly, fully apt, if it manifests the agent's competence in both archery dexterity and shot selection.

It remains only to make explicit the analogy of archery to human cognition, which seems obvious once pointed out. We need only think of a judgment that $\mathrm{p}$ as aimed at truth, as an attempt to get it right on the question whether $\mathrm{p}$, by affirming that $\mathrm{p}$ (and by doing so aptly).

Dispositional judgmental belief is then a state disposing you to judge affirmatively upon considering the question whether p. But this too is agential, and even an action, one extended temporally like the action of those motionless human statues at tourist sites. It is a sustained policy that resides in the will. (That is how Descartes could propose that we give up all our judgmental beliefs in one fell swoop, by an act of will. This is like giving up in one go all of the policies that make one a safe driver, such as stopping at yellow lights and signaling one's turns.)

3:AM: What makes it distinctive from rival theories of knowledge? Are you still trying to answer Plato's questions about knowledge-what knowledge is and what's its value and is it that second question that adds interest to your work?

ES: Yes, my footnote to Plato has been focused on those questions. In my view there is a level of human knowledge that involves just getting it right aptly. This "animal" epistemic level is an inferior level in just the way of Diana's long shot in the dark while drunk. That shot is inferior in a certain respect if too poorly selected as a hunter's archery shot, even if not quite as poorly selected as would be a shot aimed at the moon. Even if Diana's too risky shot turns out to be apt by attaining success through sublime archery dexterity, it is still inferior in the particular respect of being so risky and hence so poorly selected. So now what exactly is required for the superior "reflective" knowledge, and for "knowledge full well"?

First we must distinguish judging from guessing. Judgment is affirmation with the intention to thereby affirm competently enough, and indeed aptly. That distinguishes judgments from mere guesses. The quiz show contestant does endeavor to affirm correctly (and thus win the prize), while taking his affirmation to be a sheer guess, far from apt epistemic performance. 
A lucky contestant's affirmation is thus "alethic." It is aimed at truth alright, at getting it right. But it is still just a guess, not a judgment. In order to qualify as a judgment, an affirmation must aim at getting it right aptly, through competence, and not just through a lucky guess. Given its more substantial aim, a judgment is apt only if its constitutive alethic affirmation is not only apt but aptly apt. The subject must attain aptly not only the truth of his affirmation but also its aptness. And that in turn requires not only the proper operation of one's perception, memory, inference, etc., but also that one deploy such competences through competent epistemic risk assessment.

The analogy to Diana's two levels of assessable performance is exact.

However, spheres like the game show are devoid of risk standards. An agent who endeavors in such a sphere can still aim to minimize risk, and also to keep risk below a certain level. But that would be a subjective choice, one made relative to whatever that agent happens to care about at that point, which will determine the relevant risks and rewards. Missing from such a case are any domain-inherent standards that determine whether risk is or is not above a threshold of acceptability.

By contrast, take a tennis player barely ahead in a match, who starts hitting strokes at the top of his power and as flat as possible, so that the risk of balls going out is unacceptably high. Not unacceptably high relative to his objective of scandalizing the fans. Rather, unacceptably high relative to the objective of winning the match.

A hunter archer can also be out to shock by taking crazy shots. What makes his shots "crazy" is set by excessive risk, judged by hunting-archery standards, which would tend to draw agreement from knowledgeable observers. I am thinking that hunting-archery is similar to tennis this way, if much less formally. For one thing, there isn't a formal definition of success (as there is in tennis with winning the match). Archery hunts seem to fall into a family, depending variously on the prey hunted for, the size and organization of the hunting party, the purpose of their hunt. Most similar to formalized athletics is hunting for sport. The fully apt hunting archery shot is then determined by how well the archer assesses risk relative to hunting archery, or to their specific sort of archery hunt (whether for ducks, on foot, or for foxes, astride a galloping horse, etc.), and to the ends proper to such sport.

3:AM: So what do you mean by epistemic normativity?

ES: I mean an epistemic normativity of judgments as attempts. Consider the part of epistemology containing Plato's questions as to the nature and value of knowledge: the theory of knowledge. This is associated with the problems 
of skepticism, of whether and how we can ever attain knowledge. This part of epistemology is then concerned with the normativity of judgments as attempts. Of course, the domain of these attempts is not the domain of archery shots on physical targets. It is a domain of intellectual shots, of judgmental attempts to get it right on a given question, and to do so aptly.

3:AM: Isn't a problem for this idea that suspending a belief admits the same epistemic normativity as having the belief itself? How do you address this?

ES: This very pertinent question does raise a problem. But the problem has a solution, one that requires clarity on the fuller aim involved in many domains of human performance. Go back to the important difference between Diana and the Olympic archer. For the huntress, selecting an appropriate target is of crucial importance, and the quality of a shot can vary in that specific respect: in how well selected it is. But her forbearing from shooting in a given instance, especially when tempted, may itself be evaluated in line with our normativity of attempts. The relevant normativity is hence not just one of attempts as attempts. It is rather one of attempts or forbearings.

Sometimes the right choice, in an archery hunt, is to forbear. But consider again factors external to the hunt: impressing someone, say, or getting some exercise, or relieving someone's depression. None of these has any bearing on the assessment of that forbearance as a hunting-archery performance. Forbearances too are hunting-archery performances, and clearly assessable as such.

When the risk of failure is too high, the right choice is to forbear. And here again it is important to distinguish the respect in which the choice is right. Again, the relevant normativity is here distinctive not just of attempts but of attempts and forbearings. One's fuller objective is to make the attempt if and only if it would be apt. One must hence avoid inaptness and hence incompetence. But one does not avoid incompetence if one makes an attempt whose likelihood of success is too low. This seems little more than analytic: when the performance is in a domain that imposes standards of risk, attempts may or may not meet such standards. And the relevant competence of agents then includes reliably enough meeting those standards. (None of this applies, of course, to instances of freespirited, blasé choice, in an "unregulated" sphere, devoid of any such standards.)

Suspending judgment is thus a special case of forbearing from attempting. Accordingly, the normativity of such attempt-forbearing has a special case in the normativity of judgment-forbearing, that of suspension of judgment.

At agential junctures in a domain with distinctive aims and standards of risk, one performs. Given an end in that domain, two options open up: aiming for that 
end, or forbearing. The proper broader aim of the performance is then to make an attempt if and only it would be apt (and otherwise forbear).

The will here again has a role in epistemology. We saw earlier how judgmental beliefs are sustained policies to answer a whether question affirmatively, in pursuit of truth and aptness of affirmation. Now we find a different epistemic policy, that of aiming to make alethic attempts if and only if they would be apt. There are then two ways of violating this policy.

One might make an attempt when it is false that one would succeed reliably enough with such an attempt, so that the attempt is incompetent and hence not one that would be apt.

Alternatively:

One might fail to make an attempt when one's attempt would succeed reliably enough.

Either way one lowers the relevant quality of one's first order competence in that domain. Either the breadth or the reliability of the competence is then reduced. Lowered reliability obviously yields a lesser competence. But lowered breadth does so as well. No doubt one's competence would be superbly reliable if one tried only on the rare occasions when the conditions easily assured success. One's policy might be to shoot only when the target was a foot away. But this would be an unimpressive competence.

There's a history to this approach. At an epistemic juncture, the Cartesian objective, one highlighted by my virtue epistemology, is that of making an alethic attempt if and only if it would be apt. This is to be distinguished from the Jamesian objective of attaining truth and avoiding falsehood. This is crucial to understanding Descartes's epistemology as laid out in his Meditations and Principles. Thus, consider his account of the "error" to be avoided. The distinction made in the following passages (translations by John Cottingham) is just that between apt and inapt judgment, but of course Descartes's project in the Meditations is to attain such aptness of judgment, and to avoid error: that is, to avoid inaptness. So, his objective was not just the Jamesian objective. It was his own distinctively Cartesian objective (like one found also in Aristotle, as we shall see below).

If “... I simply refrain from making a judgment in cases where I do not perceive the truth with sufficient clarity and distinctness, then it is clear that I am behaving correctly and avoiding error [Latin error, French erreur]. But if in such cases I either affirm or deny, then I am not using my free will correctly. If I go for the alternative which is false, then obviously I shall be in error; if I take the other side, then it is by ... chance [French hasard] that I arrive at the truth, and I shall 
still be at fault.... In this incorrect use of free will may be found the privation which constitutes the essence of error." (Meditations, IV.12.)

It is also certain that when we assent to some piece of reasoning when our perception of it is lacking, then either we go wrong, or, if we do stumble on the truth, it is by accident, so that we cannot be sure that we are not in error. (Principle 44 of the Principles of Philosophy.)

In this respect, Descartes's epistemology is a special case of Aristotle's virtue ethics (translations and glosses by Robert Bolton, unpublished).

It is possible to produce something that is grammatical either by chance or under the supervision of another. To be proficient in grammar, then, one must both produce what is grammatical and produce it grammatically, that is, in accord with [kata $=$ as an expression of] knowledge of grammar in oneself [not in some supervisor]. (Aristotle, Nicomachean Ethics II4, 1105a22-6)

This is in effect our concept of aptness. How crucial such a concept is to Aristotle's ethics may be seen in the following passage:

... human good proves to be an activity of soul [a successful one, presumably, given the importance of lucky externalities for Aristotelian flourishing] in accord with [kata=as an expression of] virtue and, if there are more virtues than one, in accord with $[\mathrm{kata}=$ as an expression of $]$ the best and most complete. (Nicomachean Ethics I 7, 1098a16-17)

Since human good is what humans ought to pursue, the pursuit of interest to Aristotle is then such activity of soul, that which constitutes human good, namely activity that attains desiderata, where the attainment is in accord with virtue. Aristotle is not in these passages so clearly and explicitly focused on the attainment of human good. Famously, however, he does postulate that flourishing is properly the main human end, and flourishing is activity of soul that succeeds in accord with virtue (spread over one's lifetime).

3:AM: Do you categorise this as a type of epistemological naturalism and if so what are you ruling out on the one hand and ruling in on the other by doing that?

ES: Allow me to lead up to my answer by first delving into what sort of risk assessment is relevant to aptness, and to epistemic aptness in particular. What determines whether risk of failure in a given attempt is or is not too high? As suggested earlier, not every possible consequence that matters to those affected will bear on the relevant "risk." The risk pertinent to a particular attempt (and to its evaluation as an attempt of its sort) is the risk that the agent will fail to attain the end constitutive of that attempt. This risk of failure is coordinate with how likely or unlikely it may be that the agent will then succeed. 
The epistemic domain is a special case in which the relevant aim is getting it right on a given question, but only competently and indeed aptly. If the agent aims to make the attempt if and only if it would be apt, then a distinctive element of risk assessment becomes relevant: How probably would the agent succeed in attempting that fuller end?

In this interview I am mainly concerned with unqualified knowledge, by contrast with the varieties of expert knowledge: scientific knowledge of various sorts, legal knowledge, medically expert knowledge, and so on. When we speak of ordinary unqualified knowledge, my thought is that we are implicitly relativizing to the standards imposed by our evolution-derived humanity. These are standards that determine when we consider it appropriate to store beliefs just as a human being, rather than in one's capacity as an expert of one or another sort. Such stored beliefs are to be available for later use in one's own thought or in testimony to others. We need some standard that will determine how likely a belief is to be true given just that it is stored in one of us, including strangers that one can ask for directions, and with whom one might collaborate. Important here is the ability to count on some at least minimal default level of reliability even once the evidential basis for the stored belief is long gone from memory. This assurance is important for our own later proper reliance on our stored beliefs, and for the reliance of others on our testimony. The species-derived standard gives us a shared minimum. (This is akin to the proper ranges for volume of voice and distance between humans in face to face communication. Even if these are subject to cultural variation, they all lie within certain default humanity-wide standards. These "etiquette" standards are not formulable linguistically except trivially, and epistemic standards seem likewise implicit and inarticulable.)

3:AM: In your Locke Lectures you address two skeptical issues-dream skepticism and the question of the criterion. Taking the first one first, what are the challenges of dream skepticism?

ES: When you dream, your perceptual (and other) competence is affected. You are then unable to get it right competently with the beliefs in your dream. Consider now perceptual judgments made in your armchair some evening, while viewing a fire in your fireplace. It is thought that for all you know you might then be just dreaming that you see flickering flames, hear logs crackle, and feel warmth coming from a fire. In your dream, moreover, you might judge that you do perceive such a fire. And it is nearly always assumed that this judgment in your dream would be a real judgment. If that is so, and if, in your condition, you are incompetent to tell whether you are perceiving or only dreaming that you 
perceive, then here is your predicament: Even if you are in fact perceiving the fire perfectly well, and judge accordingly, your judgment cannot be knowledge. Too easily might you have been dreaming, as you will be only minutes later. And so, the skeptic concludes triumphantly, you cannot then know that you face a fire, since you might so easily have been wrong in so judging.

3:AM: How do you push back?

ES: Virtue theory seems as vulnerable as the next epistemology to such skeptical attack. But it has more than one line of defense. For one thing, it can resist the dream skeptic's inference from 'In his dream, S judges that p' to 'In reality, $S$ judges that $\mathrm{p}$, albeit while dreaming. That is a response developed in some detail in those Locke Lectures (A Virtue Epistemology), and it seems available to other epistemologies, not just to virtue epistemology.

Another response is more distinctive of the virtue approach. It likens the dream scenario to the notorious fake barns scenario (where your location is rife with mere façades). Arguably, if you view a real barn in bright sunlight and close by, while fully alert and otherwise in good shape, then you do know whether or not you see a barn. You have "animal" knowledge, says my virtue theory, through the first-order aptness of your judgment. You attain aptness by judging while in good shape and in a good situation (good light, good distance, etc.), through the exercise of good barn-sorting epistemic competence. (Note, by the way, how naturally the term 'good' fits in the preceding sentence, and how obviously it relates to reliability.)

You do still lack another kind of knowledge, however, namely "reflective knowledge full well." This you lack because your risk assessment is not competent when you consider yourself well enough situated to avoid the risk of failure in the claim that you see a real barn. Your actual situation is adequate because in it appearance does match reality, and you have no sufficient reason to question the default assumption that it does so. But this match is too accidental (when the locale is rife with illusion) so that it is not competently taken to be present (not with the complete SSS-competence that requires of the agent not only skill but also adequate shape and situation). Lacking such competence, one cannot know full well that one sees a real barn.

That same response is similarly effective against the dream skeptic. Even when you might very easily be dreaming, you can still know of a facing fire through your multimodal perception of it. When you are thus epistemically well situated and in good shape, your accurate judgment manifests relevant perceptual competence, and is hence apt, which makes it a case of (animal) knowledge. All 
the same, consider your good shape and situation (awake, alert, eyes open to an unobstructed view). Given how easily you might then be dreaming, such good shape and situation are too fragile to permit a competent enough assumption (a taking-for-granted) that they are reliably present. And this precludes knowledge full well that you face the blazing fire.

Virtue epistemology thus offers two distinct responses to the dream skeptic. Note, however, the important difference between them: the second protects only our animal knowledge, whereas the first protects not only our animal knowledge but also our knowledge full well.

3:AM: And how should we understand the question of the criterion? What's at stake?

ES: How can we know that we do enjoy so much as animal knowledge that p? In order to feel secure that we do, we must defeat the radical skeptic who puts it all in doubt. So an adequate response to the skeptical challenge is at stake.

Our bi-level animal/reflective approach allows the use of basic foundational faculties in attaining a second-order assuring perspective. We can thus gain awareness of those competences through whose exercise we attain our first-order knowledge.

This is the project that Descartes pursues in his Meditations by building his theological bulwark against the aggressive skeptic, through his faculties of intuition and deduction. This leaves readers agape, as they wonder how so great a thinker could suppose that blatant question-begging would prompt anything but ridicule.

3:AM: And how does your approach solve the problem?

ES: The vicious circularity objection has been a mainstay of skeptical thought from ancient times through recent journal issues. But what is the alternative to the virtue epistemological approach, as pursued for good example by Descartes? Should we demand an account of our knowledge in general that lays out justifying reasons for every bit of our knowledge, without circularity or infinite regress? No, it quickly becomes obvious that this is not only unfulfillable, but that it is obviously, necessarily unfulfillable, with metaphysical necessity. A further incoherence relates the knowledge that the aim is obviously impossible to the desire for its realization. These two attitudes do not cohere properly. One cannot coherently desire that $\mathrm{p}$ while knowing that it is obviously metaphysically impossible that $\mathrm{p}$.

But we needn't insist on the terminology of "coherence." The targeted combination is in any case bad. It is bad to want something that not even God could attain, especially when the impossibility becomes obvious. There is now a strong reason to try to escape that bad situation. But there's not much to be done about the impossibility. One must instead get rid of the desire. 
Once that is all clear enough, consider now the circularity that a successful account inevitably involves. A successful account enables us to understand human knowledge in general. Now, in coming to know our general account, we need to employ some subset of our basic competences. Since general, however, that account must give us an understanding of those very competences and their reliability. So, the competences by means of which we come to know our account must be among the competences invoked in explaining how one would know any such account, and so they must be among the competences that our account claims to be reliable. There is no vice in this sort of circularity.

Compare the circularity involved in coming to understand how our faculty of vision gives us reliable access to our surroundings. In arriving at the relevant theory about the specifics of our faculty of vision we will presumably use our eyes to gather relevant data. Based on such data we come to know about the optic nerve, the structure of our eyes, the rods and cones, etc., so as to explain how it is that vision gives us reliable access to the shapes and colors of objects around us. In reliably arriving at that theory we thus exercise the very faculty whose reliability is explained by the theory. There is no vice in this sort of circularity.

Briefly put: Suppose we wonder whether we should trust the deliverances of our basic epistemic competences. If those are indeed our basic competences, then in order properly to satisfy our curiosity we will inevitably rely on one or more of them. So, either we squelch our curiosity or we will have to fall into the circularity or regress to which the skeptic objects. Since the actual infinite regress is of reach for finite humans, we must fall into the circularity, the Cartesian sort of circularity, wherein we use our fundamental faculties (intuition and deduction, as they might be) in order to attain a picture of ourselves and the world around us (ourselves in the lap of a benevolent omnipotence) that enables us to endorse our use of those very faculties. There is no hope for a properly supportive perspective on our basic faculties that is not acquired by means of such inquiry.

Finally, if broadest science takes the place of unaided theology, and our empirical faculties supplement the a priori faculties of intuition and deduction, that gives us a better chance for a defensible perspective that can still play the sort of role sought by Descartes.

3:AM: Along the way you talk about the role of intuitions and what role they have in philosophy. Herman Cappelen has recently argued that intuitions play no role, Josh Knobe's experimental philosophy crew warns that they can lead us astray, and some Kantians say the problem all stems from bad translations of his First Critique-what do you say? 
ES: In my view, to deny that intuition has a place in the epistemology of philosophy is like denying that observation has a place in the epistemology of the empirical sciences. Do experimenters make much use of the word 'observation' or of the concept of observation? I doubt it. There is anyhow little need for them to do so. Of course, they need to make observations of various specific sorts. They must make observation reports too, as they record various instrument readings. But there is no need for the scientist to go into whether an observation was made, nor into the who, what, when, or where. The data on which scientific theorizing is based are rather the propositional contents of the instrument readings recorded, or the facts detected thereby.

Analogously, philosophers need not much use the word 'intuition' or the concept of intuition, except when they happen to be working on the epistemology of the a priori. Philosophers do need to have intuitions of various specific sorts: ethical, metaphysical, etc., depending on their targeted subject matter. And they must make intuition reports, as they record the contents of their intuitions. But they need not go into whether an intuition has been enjoyed. The data on which philosophical theorizing is based are rather the intuited contents themselves, concerning the various thought experiments. At least that is so outside the epistemology of the a priori.

When there are conflicts of observation, when experiments cannot be replicated, scientists may then retreat to a study of the various specific observations so as to explain the conflict, in the course of which they would make use of the concept of observation, or of some specification of that concept.

Similarly, when there are ostensible conflicts of intuition (or of intuition with observation), philosophers may then retreat to an explicit study of the various specific intuitions so as to explain the conflict, in the course of which they would make use of the concept of intuition, or of some specification of this concept.

We can thus see why the concept of intuition is more often used in philosophical theorizing than is the concept of observation in scientific theorizing (proportionately). One reason is that there is (proportionately) more ostensible conflict of philosophical intuitions than there is ostensible conflict of scientific observations.

So much for the use of a concept of intuition in philosophical theorizing. But how is the phenomenon itself best understood?

Here we need a distinction. Intuitive seeming is in my view an attraction to assent based on nothing more than understanding of the content that upon consideration attracts one's assent. But such understanding-based attraction can 
differ dramatically in epistemic quality. Some such attractions represent nothing more than superstition or bias absorbed from the culture, sans ratiocination.

What makes an attitude just understanding-based is that there is no rational basis, no rationale that provides a sufficient motivational basis on which one holds that belief, not even indirectly via memory (so that one holds it indirectly for the reasons based on which it was initially acquired). This is what happens with much of our common sense background knowledge, including general components of folk physics, psychology, and morality. These are "absorbed" from the culture, sans "ratiocination," as Wittgenstein puts it in On Certainty. So, they are "intuitive" that way. All this means is that they have no sufficient rational basis. They are not acquired through reasoning that eventuates in the formation of a specific belief. Rather, "light dawns gradually on the whole" of Moorean common sense. These are not things taught in elementary school. Rather are we predisposed to acquire such beliefs by our brains, as a gift of evolution, so that with a proper stream of experience we eventually emerge through infancy and childhood with such a body of beliefs, some eventually made explicit at least partially, with increasing linguistic ability (which is also how we soon attain vast knowledge of our mother tongue). Still, even once these absorbed beliefs are made explicit, it's not as though we form them by rational reliance on specific perceptual or other evidence, properly so-called. This is not to say that experience has no causal influence on their formation. It is only to say rather that the process whereby these basic principles are acquired is not one of rational argumentation whereby we rationally base a conclusion on certain premises adduced in its support.

The problem this raises is that much superstition and bias is also acquired thus without specific ratiocination. Such nonsense is also too often acquired through cultural absorption. So it can't be the mere fact of being thus acquired that provides proper epistemic status. True, that might provide some minimal "rational" status, as a basic commitment that survives deep reflection. But this is not enough to give it proper epistemic status, not fully enough, since someone deeply enough committed to such superstition or bias might sustain their nonsense even under conditions of deep reflection.

Hence the absorption does give rise to intuitions, defined as seemings based on nothing more than understanding as far as rational basing is concerned. Such intuitions differ crucially from intuitions that are, let's say, rational. These latter are distinguished by the fact that they are sufficiently reliable. So, the more specific way they are acquired and sustained is sufficiently reliable to constitute epistemic competence, and not just superstition or bias. 
That is in support of an analogy between observation and intuition. Far from being exhausted, however, the topic is still much debated in books, articles, and symposia, and I myself remain actively engaged.

3:AM: Tim Williamson's approach to knowledge disconnected belief from knowledge in a way-I wondered if this poses challenges to your own approach?

ES: It is certainly a different approach, even if we are in sympathy methodologically. Whether it is incompatible depends on its full content, and more specifically on what it means to say that knowledge is "first." Is it first conceptually, so that we understand other epistemological concepts in terms of our concept of knowledge? That I do find agreeable.

Here's just one example of how that might work. Take concepts such as justification or competence, and more specifically their epistemic variants. Suppose it is not possible to understand such epistemic concepts without appeal to knowledge. Perhaps "epistemic justification or competence" must be understood conceptually as just "the sort of justification or competence that a belief needs to manifest in order to qualify as knowledge." If we have a better understanding of knowledge than we do of such justification or competence, then we can explain the latter through the former.

Epistemic competence might be thus posterior to knowledge conceptually, however, while still prior metaphysically. And this latter is what my view implies: that animal knowledge is metaphysically constituted by apt belief, by belief whose correctness manifests the believer's epistemic competence, a relevant disposition to get it right on the matter at hand when one tries to do so.

3:AM: How does your theory understand testimony? We all rely on testimony for most of our beliefs and knowledge but where does responsibility lie for the normative requirements of testimonial justification on your understanding-the individual or features of the social relations between speakers and hearers?

ES: In my view (animal) knowledge is apt belief, where not only the belief (its existence and content) but also its correctness is creditable to the subject's competence. The problem of testimony for this view is that the correctness of much testimonially based belief is no more than minimally creditable to the believer.

Take a beginning archer whose hand is guided by an expert. Is the success of his shot then creditable to the beginner? In order to answer this question we must know more. So far we cannot tell whether the success of the shot is creditable at all, even partially, to the archer. It is of course plausible that the existence of the shot is thus creditable. The archer at least lends his hands and it is presumably up to him when exactly he lets go. So the existence of that very shot is then 
due to him at least in part. However, that leaves it wide open whether the shot's success is also creditable to him, even partially. That will depend on the likes of this: Does he or does he not at all affect the arrow's orientation at the moment of release? Does he or does he not at all affect how far back the arrow is drawn at the moment of release? Crucially, he might control whether and when the arrow leaves the bow, affecting thereby the existence of the shot, without at all controlling either the tip/tail coordinates or the tension at the time of release. That being so, he might plausibly determine the existence of the shot without at all determining its accuracy.

Similarly for the case of a recipient of testimony. She too might contribute to the existence of her belief, without contributing at all to its success, to its hitting the mark of truth. But her belief will be apt only if she makes a contribution, however small, to her belief's correctness and not just to its existence. Compare the credit for a football touchdown, which might be shared by the receiver not only with the quarterback, but also with the linesmen who make crucial protective plays, etc. The success of the touchdown play depends on the receiver, it is true; but in a particular case it might depend far more on the work of others.

This I suggest as the right model for understanding how a belief (a particular, token belief) might be apt even when its correctness is more creditable to the testifier, among others, than to the recipient. The success of that belief, its hitting the mark of truth, might after all be creditable in some measure to the recipient, which would suffice for his attainment of partial credit. More would be required than just that the recipient contribute to the existence of that belief. He must also in some way contribute to its correctness. For example, if he had failed to be a careful enough listener and might too easily have misinterpreted the testifier, then he might still have been clearly responsible in part for the existence of his belief, without being sufficiently responsible for its correctness.

When I accept someone's testimony, I am thus only a small part of the full seat of epistemic competence, which might include many others in a long chain. My own contribution might then be slight, just through the perceptual and linguistic competence involved in knowing what someone is saying or writing, etc.

That is as concerns a knowledge that derives from the first-order default trust proper to rational, social animals. Defeaters can properly block the power of such a source. Absent defeaters, however, we have not only the rational first-hand trust in the testimony of a fellow human, but also the proper default trust that such trust is then in order, for a standing that goes beyond the first order and ascends to reflective endorsement. 
3:AM: I mentioned earlier experimental philosophy, but I wonder how important interdisciplinary work is to epistemology now-I'm thinking of the work going on in neuroscience and psychology and philosophy of mind too. How interdisciplinary is epistemology?

ES: Epistemology now flourishes with various complementary approaches. This includes formal epistemology, experimental philosophy, cognitive science and psychology, including relevant brain science, and other philosophical subfields, such as metaphysics, action theory, language, and mind. It is not as though all questions of armchair, traditional epistemology are already settled conclusively, with unanimity or even consensus. We still need to reason our way together to a better view of those issues. But that is compatible with the pursuit of other approaches to questions alongside those we take up traditionally in seminars or armchairs. I expect and hope for continuing collaboration, combining the best results of the best research along the various relevant lines of approach.

This stance is in line with the earlier suggestion that we can pursue the Cartesian project without restricting ourselves to theology and a priori faculties. A better, broader perspective is properly sought if we pursue the project with reliance on science broadly and on our full span of epistemic competences, including the empirical as well as the a priori.

3:AM: And finally can you recommend five books to the readers here at 3:AM that will take us further into your philosophical world?

ES: My studies in college and graduate school included no epistemology, apart from historical texts like those of Aristotle and Descartes. Only later, welcomed by Roderick Chisholm, did I enter the philosophical world well represented in Epistemology (Wiley), the large anthology edited by Fantl, Kim, McGrath, and Sosa.

In my long career I have learned so much from so many that there's no hope of selecting five without qualification. Anyhow, in my immediate neighborhood within that world, the following four approaches are notably similar to my own, though also dissimilarly dissimilar no less notably. Listed in temporal order:

Alvin Plantinga, Warrant and Proper Function

Linda Zagzebski, Virtues of the Mind

Duncan Pritchard, Epistemic Luck.

John Greco, Achieving Knowledge 